\title{
Thyroid Doses in Children from Radioiodine following the Accident at the Fukushima Daiichi Nuclear Power Plant
}

\author{
Eunjoo Kim, Osamu Kurihara \\ National Institutes for Quantum and Radiological Science and Technology, Chiba, Japan
}

\section{Invited Paper}

Received December 24, 2019

Revision March 17, 2020

Accepted March 18, 2020

Corresponding author: Osamu Kurihara

Department of Radiation Measurement and Dose Assessment, Center for Advanced Radiation Emergency Medicine, National Institutes for Quantum and Radiological Science and Technology, 4-9-1 Anagawa, Inage-ku, Chiba City, Chiba 263-8555, Japan

Tel: +81-43-206-4734

Fax: +81-43-284-1769

E-mail: kurihara.osamu@qst.go.jp

This is an open-access article distributed under the terms of the Creative Commons Attribution License (http://creativecommons.org/licenses/by-nc/4.0), which permits unrestricted use, distribution, and reproduction in any medium, provided the original work is properly cited.

Copyright $\odot 2020$ The Korean Association for Radiation Protection

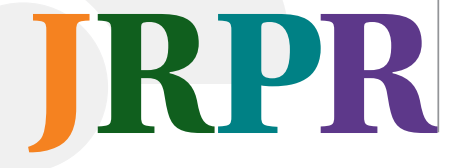

Background: Huge amounts of radionuclides were released into the environment due to the Fukushima Daiichi Nuclear Power Plant (FDNPP) accident, which caused not only serious contamination on the ground, but also radiation exposure to the public. One problem that remains in performing the dose estimation is the difficulty of estimating the internal thyroid dose due to the intake of radioiodine (mainly, ${ }^{131} \mathrm{I}$ ) because of limitations to the human data available.

Materials and Methods: The relevant papers were collected and reviewed by the authors. The results of thyroid dose estimates from different studies were tabulated for comparison.

Results and Discussion: The thyroid dose estimates from the studies varied widely. The dose estimates by the United Nations Scientific Committee on the Effects of Atomic Radiation were higher than the others due to the ingestion dose being based on conservative assumptions. The dose estimates by Japanese experts were mostly below $20-30 \mathrm{mSv}$. The recent studies suggested that exposure on March 12, 2011 would be crucial for late evacuees from the areas near the FDNPP because of the possible intake of short-lived radionuclides other than ${ }^{131} \mathrm{I}$. Further multilateral studies are vital to reduce uncertainties in the present dose estimations.

Conclusion: The estimation of the thyroid doses to Fukushima residents still has many uncertainties. However, it is considered unlikely that the thyroid doses exceeded $50 \mathrm{mSv}$ except in some extreme cases. Further multilateral studies are thus necessary to reduce the uncertainties in the present dose estimations.

Keywords: Fukushima, Nuclear Accident, Iodine-131, Thyroid, Dose Estimation

\section{Introduction}

The Fukushima Daiichi Nuclear Power Plant (FDNPP) run by the Tokyo Electric Power Company (TEPCO) was damaged by the Great East Japan Earthquake and subsequent massive tsunami on March 11, 2011, which led to a serious nuclear accident with an enormous release of radioactive materials into the surrounding environment [1]. More than 8 years have passed since this accident; however, there remain areas where the ambient dose rates are significantly elevated due to the radionuclides deposited on the ground (mainly, ${ }^{137} \mathrm{Cs}$ at present) and a large number of Fukushima residents have been obliged to evacuate from their hometowns.

It is necessary to evaluate the potential radiation exposure doses to persons involved in the FDNPP accident, in particular Fukushima children. Extensive efforts to do so by 
Japanese experts have been described elsewhere [2]. One consensus view of the relevant studies was that both external and internal doses to residents were expected to be low in general, and thus radiation-induced health problems would not be notable in the future. However, one critical problem that remains is that there are many uncertainties in the estimation of thyroid doses, mainly from the intake of radioiodine that existed only during a short period of time after the accident. The isotope making the biggest contribution to the internal thyroid dose was ${ }^{131} \mathrm{I}$, with a physical half-life of 8 days, which was also the case in the Chernobyl Nuclear Power Plant (NPP) accident. However, the number of direct human measurements of ${ }^{131}$ I was very limited in the FDNPP accident.

Fukushima Medical University began performing extensive health examinations for residents, named the Fukushima Health Management Survey (FHMS), at the end of June 2011, on commission from Fukushima prefectural government [3]. The FHMS consists of the Basic Survey (external dose estimations) and the Detailed Surveys. One component of the Detailed Surveys is the thyroid ultrasound examinations performed to detect thyroid diseases as early as possible, targeting approx. 370,000 residents aged 0-18 years at the time of the earthquake. As a result, approx. 200 malignant cases (including suspected malignancies) were found as of December 2017 (http://www.pref.fukushima.lg.jp/site/ portal/43-7.html). The Exploratory Committee of the FHMS stated that these malignant cases were unlikely to be caused by radiation exposure because thyroid doses were expected to be much lower than those in the Chernobyl NPP accident. However, the committee also claimed that further studies were necessary to clarify this issue (http://www.pref.fukushima.lg.jp/uploaded/attachment/158522.pdf).

This paper provides a review of the published literature on the thyroid dose estimation, mainly for Fukushima residents, together with additional explanations and a discussion of the relevant problems. Note that the thyroid dose was caused by external radiations as well; however, this was not a focus here because of the relatively small contribution of external exposure compared to internal exposure.

\section{Methods for Estimating Internal Thyroid Doses}

This section describes the main methods used for estimating internal thyroid doses in the FDNPP accident. In general, internal dose estimation is more complicated than external dose estimation because the internal dose cannot be directly measured and is associated with many assumptions made by the assessors. The sources mainly used for the internal thyroid dose estimation are two-fold: direct (in vivo) measurements and environmental data.

The direct measurements refer to measurements of radionuclide(s) in the human body using a photon detector placed near the subject [4]. This method is available when the radionuclide(s) of concern emits photons with enough high energy to penetrate the body tissue and an abundant yield. Regarding ${ }^{131} \mathrm{I}$, the most detectable photon energy line is $365 \mathrm{keV}$ (81.7\%). The detector used is typically placed near the front bottom of the neck since iodine is localized in the thyroid. Before the measurements are made, the detector needs to be calibrated using suitable phantoms that mimic the human thyroid and neck [5]. It is noted that direct measurements can tell only the body content $(\mathrm{Bq})$ at the time of the measurement. For the internal dose estimation, reasonable assumptions regarding the intake day(s), the route of intake (inhalation, ingestion, injection), and the physicochemical characteristics of the radioactive materials of concern are essential.

The environmental data available for internal dose estimations are the radioactivity concentrations in air, food and drink items, and so on. However, unfortunately, such data were not adequately obtained during the early period when a detectable amount of ${ }^{131} \mathrm{I}$ existed in the environment. In fact, continuous air sampling was not carried out within Fukushima Prefecture at that time. It was found later that air sampling filters collected by suspended particulate matter monitors installed at many locations to detect air pollutants would be potentially available for the internal dose estimation [6]. However, the exact intake amount is difficult to determine unless other information is obtained, such as the indoor dose reduction factor for airborne radioactive materials, the respiration rate during exposure, the food and drink consumption during emergency situations, the actual effects of radiation protection measures taken by authorities and/or individuals, and so on. In terms of the inhalation of radioiodine, the chemical composition also needs to be determined because the dose coefficients (Sv per Bq intake) differ among its chemical forms: elemental iodine, methyl iodide and particulate iodine. Consequently, the internal dose estimation based on the environmental data is likely to involve considerable uncertainties. On the other hand, information on the 
chemical composition of iodine is not necessarily required in the dose estimation based on the direct measurements described above. However, it should be noted that such dose estimations also contain uncertainties related to assumed intake scenarios.

In the Chernobyl NPP accident, models of the transfer of radionuclides from the environment to cow's milk were used to estimate the internal thyroid doses of residents in contaminated territories $[7,8]$. These models assumed that the residents continued to consume milk contaminated with ${ }^{131} \mathrm{I}$ for a certain period of time, which was considerably different from the situation in the FDNPP accident. A survey of the food supply system suggested that consumption of the contaminated food and drink items by residents would have been limited shortly after the accident due to prompt countermeasures and the collapse in supply chains in the prefecture [9].

\section{Review of the Relevant Publications}

This section provides a brief review of the publications relevant to estimations of the internal thyroid doses to Fukushima residents, in particular the doses in the areas radiologically affected by the accident. Table 1 provides a summary of the dose estimations for children from the publications described below.

\section{Estimation from Direct Measurements for ${ }^{131} \mathbf{I}$}

This category provides the most reliable dose estimates; however, the number of measurements was limited. The largest dataset in this category was obtained from the screening campaign by the Nuclear Emergency Response Local Headquarters at the end of March 2011 [10, 11]. This campaign was performed in Kawamata town, Iwaki city, and Iitate village only. Moreover, these three municipalities are located mostly outside of the $30-\mathrm{km}$ radius of the FDNPP, within which either evacuation or sheltering indoors was ordered right after the accident; however, internal thyroid exposure to children living in the areas was expected to be high based on predictions made by atmospheric transport dispersion model (ATDM) simulations. In the campaign, 1,149 subjects were recruited and internal thyroid doses were estimated for 1,080 of the subjects, demonstrating that their doses were much lower than the $100 \mathrm{mSv}$ dose (thyroid equivalent dose) predicted by the ATDM simulations for hypothetical 1-year-old children who remained outdoors all

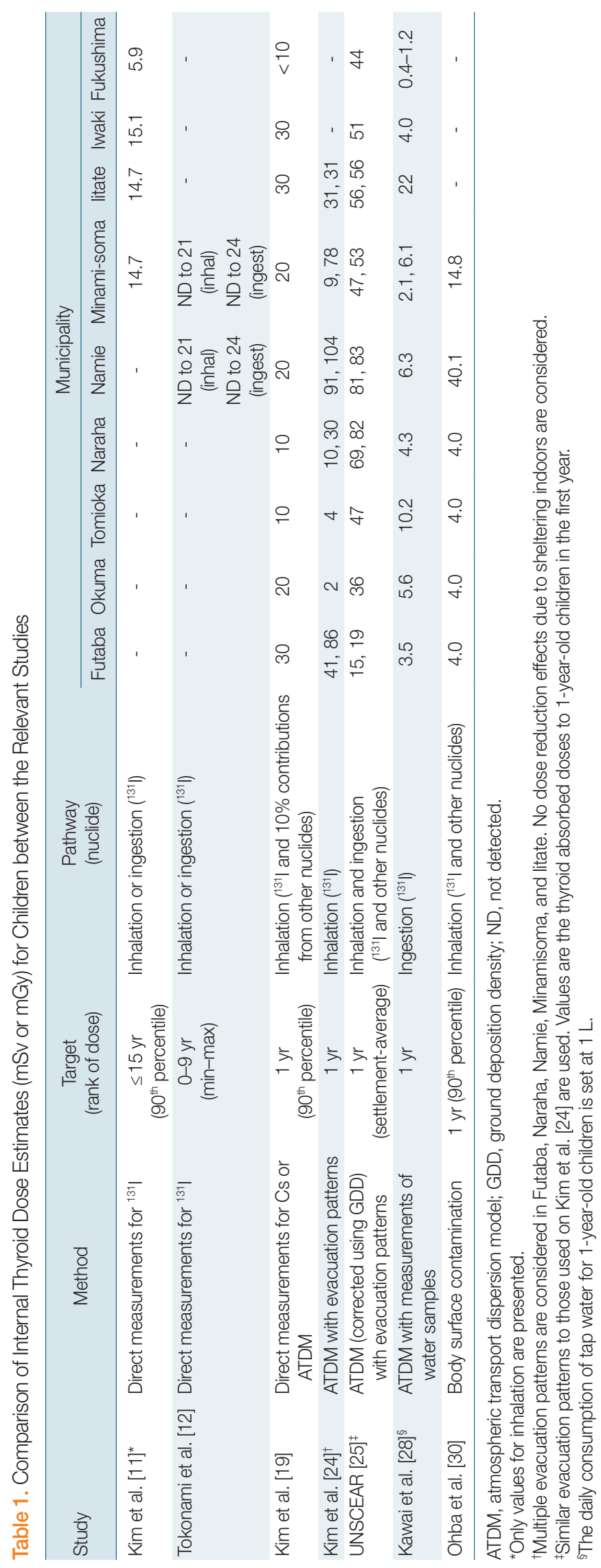


the time. The level of $100 \mathrm{mSv}$ was regarded as a cutoff level in the screening; no measures were supposed to be taken for persons below this level. The results of the assessment of the 1,080 subjects' thyroid doses were provided in the present authors' latest paper [11]. As a result, the thyroid doses were less than $30 \mathrm{mSv}$ for most of the subjects.

Tokonami et al. [12] independently performed their measurements during the period from April 12 to April 16, 2011. As a result, ${ }^{131} \mathrm{I}$ was detected in 46 out of 62 subjects from Namie town and Minamisoma city. The median (maximum) thyroid doses to children (under 20 years of age) and adults based on the assumption that they inhaled ${ }^{131}$ I on March 15 only were $4.2 \mathrm{mSv}(23 \mathrm{mSv})$ and $3.5 \mathrm{mSv}$ (33 mSv), respectively.

Matsuda et al. [13] performed measurements with a whole-body counter (WBC) owned by Nagasaki University. They examined 173 subjects within the first month after the accident. These subjects were mostly evacuees from Fukushima Prefecture and first responders from Nagasaki Prefecture. The average stay period of the subjects in Fukushima Prefecture was 4.8 days. As a result, ${ }^{131} \mathrm{I},{ }^{134} \mathrm{Cs}$, and ${ }^{137} \mathrm{Cs}$ were detected in about $30 \%$ of the subjects. The maximum thyroid dose (20 mSv) was found in a subject who was categorized in the earliest evacuation group with a stay period of March 1118. The thyroid dose was much lower in subjects who had stayed in Fukushima Prefecture at earlier times.

There have also been a few other reports related to direct measurements of ${ }^{131} \mathrm{I}$ [14-16]; however, the number of subjects examined in each study was very limited. Thus, regarding the general public, the number of people for whom data are available is only about 1,300 in total, which is much less than the number of persons whose thyroid doses should be carefully evaluated (e.g., children, pregnant women, delayed evacuees).

\section{Estimation from Direct Measurements for Cesium}

Fukushima prefectural government started WBC measurements at the end of June 2011 in order to clarify the levels of internal contamination in residents. These measurements have been continued to the present; the number of measurements has reached 341,430 as of September 2019 (http://www.pref.fukushima.lg.jp/site/portal/ps-wbc-kensa-kekka.html). Details on the WBC measurements conducted in the prefecture have been described elsewhere [17].

Although the WBC measurements targeted ${ }^{134} \mathrm{Cs}$ and ${ }^{137} \mathrm{Cs}$ rather than ${ }^{131} \mathrm{I}$, relatively early WBC measurements (at least those performed until the end of 2011) could be utilized to estimate thyroid doses by determining an activity ratio of these two elements. Kim et al. [18] derived the intake ratio of ${ }^{131}$ I to ${ }^{137} \mathrm{Cs}$ by comparing the thyroid and effective dose distributions for residents of Kawamata town and Iitate village at the same upper percentiles (e.g., $80^{\text {th }}, 90^{\text {th }}$, and $95^{\text {th }}$ percentiles). Here the thyroid dose distribution $\left({ }^{131} \mathrm{I}\right)$ was obtained from the screening campaign, whereas the effective dose distribution $\left({ }^{134} \mathrm{Cs} /{ }^{137} \mathrm{Cs}\right)$ was obtained from WBC measurements of adult subjects. The lower percentile or median values for the two dose distributions were not used due to the low detection rates in both measurements. The intake ratio was also introduced based on the assumption that adults and children in the same municipality inhaled ${ }^{131} \mathrm{I}$ and ${ }^{137} \mathrm{Cs}$ with the same activity ratio, but with different respiratory volumes depending on age. As a result, the intake ratio of ${ }^{131} \mathrm{I} /{ }^{137} \mathrm{Cs}$ was derived to be $2.4-3.3$ for Kawamata town and 2.0-2.3 for litate village. Using the derived intake ratio of 3 (as a rounded average), Kim et al. [19] presented estimates of the $90^{\text {th }}$ percentile thyroid doses to 1-year-old children based on the effective dose distributions for adults from several municipalities [19]. The estimate for 1-year-old children was 30 $\mathrm{mSv}$ as the $90^{\text {th }}$ percentile value for the relatively high dose areas. A similar approach to this was also attempted for Namie town's residents by Hosoda et al. [20] and Kim et al. [21], resulting in a large discrepancy in the derived intake ratio of ${ }^{131} \mathrm{I} /{ }^{134} \mathrm{Cs}$ : 0.1-0.9 (a geometric mean, 0.2) and 3-5 (average, 3.8), respectively.

One question addressed in these studies is for how long a trace of the early intake remains in WBC measurements. In this regard, it should be noted that the biological half-life of cesium is much shorter in children than in adults. In WBC measurements over the period between June 27 and July 28, 2011, the ratios of subjects with the presence of both ${ }^{134} \mathrm{Cs}$ and ${ }^{137} \mathrm{Cs}$ in adults and children were $28.8 \%$ and $4.1 \%$, respectively [21]. An overestimation of the cesium intake is also likely to occur in children based on an acute intake scenario on potentially the earliest day [17]. On the other hand, it has been found that the cesium detection rate tends to be higher in late evacuees from areas near the FDNPP in the case of adult subjects, suggesting that a trace of the early intake would appear in the WBC measurements until about half a year after the accident [22, 23].

\section{Estimation from Other Sources}

Kim et al. [24] estimated the internal thyroid doses to resi- 
dents using the results of ATDM simulations and 18 evacuation model patterns. In this estimation, a dose reduction factor due to sheltering indoors was not factored in considering inhalation as an exposure pathway of concern. From direct measurements, the estimated thyroid doses were found to exist around the upper levels of the estimated doses. The United Nations Scientific Committee on the Effects of Atomic Radiation (UNSCEAR) also estimated internal doses from inhalation using other ATDM simulations, but indirectly, by using a ratio obtained in the simulations, namely the relationship between the ground deposition density (GDD) and the time-integrated air concentration [25]. Regarding the GDD, measurement data were available.

Measurement data for the radioactivity in food and drink items were needed to estimate the internal doses from ingestion. The UNSCEAR and the World Health Organization estimated that doses based on conservative assumptions, such as continuing the consumption of contaminated food items for a certain period of time $[25,26]$. According to the estimates by the UNSCEAR, the thyroid absorbed doses to infants ( 1 year of age), children (10 years of age), and adults in Fukushima Prefecture were 32.8 mGy, 15.2 mGy and 7.78 $\mathrm{mGy}$, respectively, only from ingestion. By contrast, Murakami and Oki [27] estimated the thyroid doses from ingestion taking into account the effects of countermeasures (as in the Case 1 scenario): $1.7 \mathrm{mSv}$ (<1 year), $2.1 \mathrm{mSv}$ (7-12 years, male), and $0.84 \mathrm{mSv}$ ( $\geq 19$ years, male) for citizens in Fukushima city. Kawai et al. [28] also reported the thyroid doses from the ingestion of tap water based on realistic intake scenarios with reconstructed time trend profiles of the ${ }^{131}$ I radioactivity concentration.

With regard to estimations from other human data, Kamada et al. [29] reported thyroid doses of 27-66 mSv based on the ${ }^{131}$ I radioactivity in urine samples. ${ }^{131}$ I was detected in urine in 5 out of 15 subjects (including 4 children) from Kawamata town and litate village; only one of the 4 children was positive in his urine sample (44 mSv). Ohba et al. [30] performed a unique dose estimation using the body surface contamination levels of evacuees from areas near the FDNPP. In this study, the intake by inhalation was derived assuming that ${ }^{131} \mathrm{I}$ in air caused body contamination by its deposition during the period when residents were potentially exposed to radioactive plumes. The $90^{\text {th }}$ percentile thyroid doses for 1-year-old children of the Namie group, the Minamisoma group, and the group comprising four municipalities (Tomioka town, Okuma town, Futaba town, and Naraha town) were estimated at $40.1 \mathrm{mSv}, 14.8 \mathrm{mSv}$, and $4.0 \mathrm{mSv}$, respectively.

\section{Discussion}

As shown in Table 1, the internal thyroid dose estimates are different among the studies. The most reliable estimates based on direct measurements for ${ }^{131} \mathrm{I}$ [11-13] were found to be below 20-30 mSv; however, the number of such estimates was limited. The relatively high estimates by the UNSCEAR [25] are, as described earlier, due to basing the ingestion doses on conservative assumptions: $32.8 \mathrm{mGy}$ for 1-year-old children in the whole of the prefecture (excluding the evacuation areas). The estimates by Kim et al. [24], which were also considered conservative in general, differed greatly among the municipalities. These estimates are only for the inhalation dose; however, they are higher than those by the UNSCEAR (including the ingestion dose) in Futaba town and Namie town, whereas they are much smaller in Okuma town and Tomioka town despite the use of 18 similar evacuation model patterns. One critical note in this study is that the evacuation behaviors of residents in the neighboring areas for the first few days after the accident would greatly influence the estimations of their thyroid doses from inhalation. In this context, one should pay attention to the fact that many residents were voluntarily evacuated even from areas where immediate evacuation was not ordered $[19,31]$, resulting in possibly averting exposure to radioactive plumes that were significant in the first week. According to the UNSCEAR, the thyroid dose averted by prompt evacuation was estimated at $750 \mathrm{mGy}$ for 1-year-old children in the neighboring municipalities [25].

The first comprehensive estimation for Fukushima residents was presented by the authors [32] in January 2013 (later published [19]). This estimation was provided only for about $90^{\text {th }}$ percentile inhalation doses in light of the fact that ingestion doses would have been minimized due to the prompt restriction of the consumption and distribution of contaminated food and drink items [33]. The estimation was mainly based on the effective doses of adult subjects according to WBC measurements and complementarily from ATDM simulations. The latter were applied to areas where direct measurement data were unavailable, such as the Aizu and Nakadori regions (the west and middle areas of Fukushima Prefecture), Iwaki city, and so on. One key factor in this estimation is the use of the derived intake ratio to con- 
vert the effective dose to the thyroid dose. It might be considered reasonable that the derived intake ratio of ${ }^{131} \mathrm{I}$ to cesium was much lower than the activity ratio of the two elements in various environmental samples (e.g., 8 for the time-integrated air concentration observed in Ibaraki Prefecture during the period between March 13 and May 23, 2011), taking into account the relatively-low thyroid iodine uptake (TIU) in Japanese populations due to their diet [18]; however, further studies on this matter are necessary.

The recent dose estimations by Ohba et al. [30] and Kawai et al. [28] are provided for the inhalation dose and the ingestion dose, respectively. The sum of these two dose estimates was also mostly less than $20 \mathrm{mSv}$ (at the $90^{\text {th }}$ percentile level) for the municipalities near the FDNPP. However, the $90^{\text {th }}$ percentile thyroid dose of the Namie group reached 46.4 $\mathrm{mSv}$ in total $(40.1 \mathrm{mSv}$ from inhalation and $6.3 \mathrm{mSv}$ from ingestion), although this value was reduced by two-thirds (30.9 $\mathrm{mSv}$ ) by taking into account the average TIU value in Japanese populations [30]. A crucial point recognized in recent studies is the date of the first exposure, which is important in terms of the dose contribution from short-lived radionuclides other than ${ }^{131}$ I. The thyroid dose only from ${ }^{131}$ I would increase by 1.59 times in the case of exposure to radioactive plumes from March 12-14 (1.09 times for exposure from March 15-17) when taking into account the dose contribution from ${ }^{132} \mathrm{Te}^{-132} \mathrm{I}$ and ${ }^{133} \mathrm{I}[30]$. This has been also pointed out by Shinkarev et al. [34]. In contrast, Kim et al. [19] set the ratio at 1.1 based on the results of continuous air monitoring at a location in Ibaraki prefecture where the first plume arrived on March 15. Our latest study [23] demonstrated that approx. $20 \%$ of Namie town's residents stayed within the 20 - $\mathrm{km}$ radius of the FDNPP as of 3:00 pm on March 12 or later, and their effective doses were considerably higher than the doses of those who had already evacuated outside the $20-\mathrm{km}$ radius before that time. This result might suggest that late evacuees from the neighboring areas were additionally exposed to radioactive plumes released from Unit 1 which caused the hydrogen explosion on the same day. In that case, the dose contribution from the short-lived radionuclides other than ${ }^{131}$ I would needed to be carefully evaluated. On the other hand, the dose received on March 15, when the largest release event occurred at Unit 2 is expected to be small because most residents had moved to distant places by that time.

In conclusion, the estimation of thyroid doses to Fukushima residents still has many uncertainties However, although the dose estimates from various studies differ, it is believed that the thyroid doses are unlikely to exceed $50 \mathrm{mSv}$ excluding some extreme cases (e.g., persons who continued to consume highly contaminated items or did not evacuate from areas close to the FDNPP). The dose reduction effects of selfprotection measures by the residents might have be significant, judging from the results of the screening campaign in litate village where tap water was significantly contaminated with ${ }^{131} \mathrm{I}$ in the early period compared to other areas. Further multilateral studies are thus necessary to reduce the uncertainties in the present dose estimations.

Finally, we would like to describe our proposed method for population monitoring in case of a future nuclear accident based on lessons learned from the experiences of the FDNPP, in particular in terms of the thyroid dose estimation of the public. The outline of this method is shown in Fig. 1.

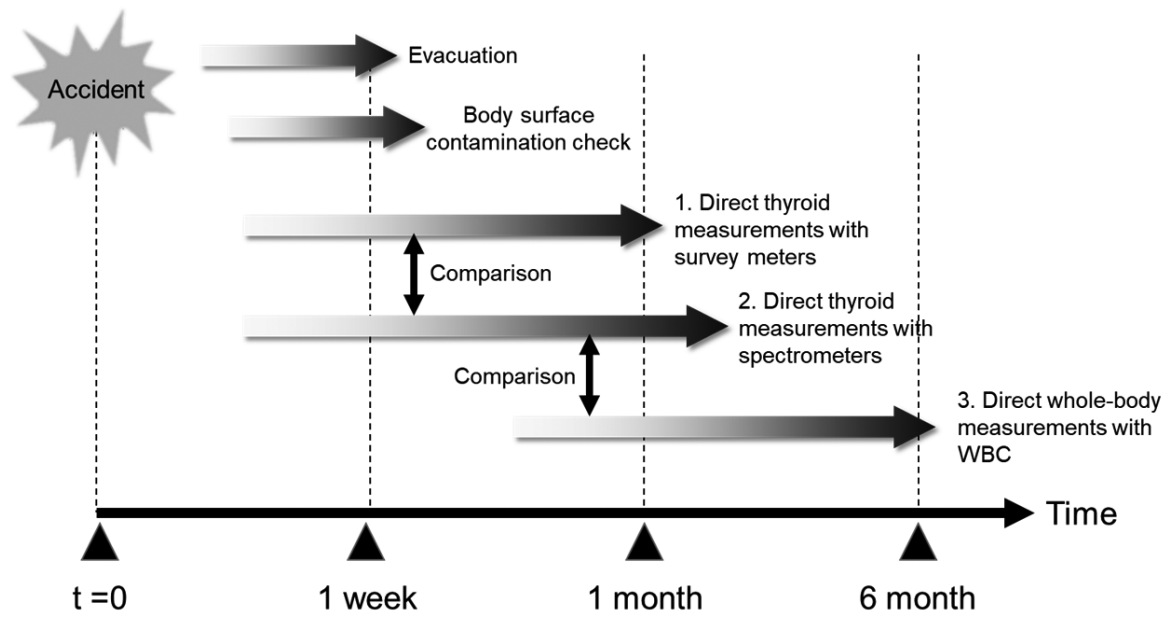

Fig. 1. Outline of the proposed population monitoring method for the thyroid dose estimation. WBC, whole-body counter. 
Note that population monitoring is carried out following evacuation of people in the areas designated based on measurement results of the ambient dose rate there. According to the Japanese guidelines for nuclear emergency response stipulated after the FDNPP accident, evacuation criteria are basically operational intervention levels (OILs): OIL1 (500 $\left.\mu \mathrm{Sv} \cdot \mathrm{h}^{-1}\right)$ for prompt evacuation and OIL2 $\left(20 \mu \mathrm{Sv} \cdot \mathrm{h}^{-1}\right)$ for protracted evacuation (within 1 week) [35]. These OIL values were arranged from the original values in the IAEA safety guides [36, 37] based on experiences of the FDNPP. The propose population monitoring method is composed of three types of direct measurements to obtain as many human data as possible for the dose reconstruction following a nuclear accident. The first type is direct thyroid measurements with survey meters (non-spectrometric devices), which are basically the same as the screening campaign conducted shortly after the FDNPP accident [10, 11]. The second type is direct thyroid measurements with spectrometric devices and third type is direct whole-body measurements with WBCs. Each type of direct measurements has advantages and disadvantages; however, would be reasonably compensated by comparing with each other. The first type measurements are intended to be performed with a main purpose of triage to identify persons who are heavily exposed. It is assumed that measurers are first responders at each site including non-radiation experts (e.g., local government officers). Survey meters (typically, a NaI(Tl) scintillation probe-type) are easy-to-use devices and suitable for quick measurements. For validation of the first type measurements, the second type measurements may be used by comparisons of the ${ }^{131}$ I thyroid contents of selected persons who undergo both types of measurements [38]. The second type measurements will provide the most reliable data for the thyroid dose estimation; however, need a longer counting time and adequate training for handling the devices. The third type measurements target ${ }^{134} \mathrm{Cs}$ and ${ }^{137} \mathrm{Cs}$ in contrast to the other two types of measurements. These measurements would be effective for persons who miss early direct measurements if an appropriate value of the intake ratio of ${ }^{131} \mathrm{I} / \mathrm{Cs}$ can be determined from the same persons with significant intake of both elements.

Apart from direct measurements of the affected populations, information on their evacuation behaviors should be collected as early as possible. This information will be essential to assume the time of intake of radionuclides together with results of environmental monitoring. The dose contribution from short-lived radionuclides other than ${ }^{131}$ I should be taken into account if a significant intake event is expected within the first few days after a nuclear accident [34]. Assuming the difficulty in measuring ${ }^{132} \mathrm{Te}^{-}{ }^{132} \mathrm{I}$ and ${ }^{133} \mathrm{I}$ in persons, it may be practical that the potential intake of these radionuclides is estimated from the measured ${ }^{131} \mathrm{I}$ thyroid content and the nuclear core inventory. In the first type measurement, it is supposed that a screening level corresponding to OIL8 [37] is determined as a net reading value of the devices used. A relatively-high gamma emission rate of ${ }^{132} \mathrm{I}$ may cause overestimations of the internal thyroid dose if the OIL8 value is derived assuming intake of ${ }^{131} \mathrm{I}$ only; however, this would not be a significant problem.

Further considerations on the proposed method will be reported in the authors' future publication. However, one thing for sure is, as experienced in the past nuclear accidents, that the number of people to be examined regarding their radiation exposure can be overwhelmingly large. It is thus crucial for each county to establish and maintain a steady and effective population monitoring system as a part of a national-level scheme for radiation emergency response [17].

\section{Conflict of Interest}

No potential conflict of interest relevant to this article was reported.

\section{Acknowledgements}

The present authors' studies were partly financially supported by the Ministry of the Environment of Japan and were performed as a joint research project with Fukushima Medical University.

\section{References}

1. National Diet of Japan. The official report of the Fukushima Nuclear Accident Independent Investigation Commission. Tokyo, Japan: National Diet of Japan; 2012.

2. Kurihara O. External and internal dose assessments of Fukushima residents after the 2011 nuclear disaster. J Natl Inst Public Health. 2018;67:11-20.

3. Yasumura S, Hosoya M, Yamashita S, Kamiya K, Abe M, Akashi $\mathrm{M}$, et al. Study protocol for the Fukushima Health Management Survey. J Epidemiol. 2012;22:375-383.

4. International Atomic Energy Agency. Assessment of occupational exposure due to intakes of radionuclides. Vienna, Austria: International Atomic Energy Agency; 1999. 
5. International Commission on Radiation Units and Measurements. Phantoms and computational models in therapy, diagnosis, and protection (ICRU Report 48). Bethesda, MD: International Commission on Radiation Units and Measurements; 1992.

6. Tsuruta H, Oura Y, Ebihara M, Ohara T, Nakajima T. First retrieval of hourly atmospheric radionuclides just after the Fukushima accident by analyzing filter-tapes of operational air pollution monitoring stations. Sci Rep. 2014;4:6717.

7. Balonov MI, Bruk GY, Zvonova IA, Pitkevich VA, Bratilova AA, Jesko TV, et al. Methodology of internal dose reconstruction for a Russian population after the Chernobyl accident. Radiat Prot Dosimetry. 2000;92:247-253.

8. Drozdovitch VV, Goulko GM, Minenko VF, Paretzke HG, Voigt G, Kenigsberg YI. Thyroid dose reconstruction for the population of Belarus after the Chernobyl accident. Radiat Environ Biophys. 1997;36:17-23.

9. Hirakawa S, Yoshizawa N, Murakami K, Takizawa M, Kawai M, Sato O, et al. Surveys of food intake just after the nuclear accident at the Fukushima Daiichi Nuclear Power Station. Shokuhin Eiseigaku Zasshi. 2017;58:36-42.

10. Kim E, Kurihara O, Suzuki T, Matsumoto M, Fukutsu K, Yamada Y, et al. Screening survey on thyroid exposure for children after the Fukushima Daiichi nuclear power station accident. Proceedings of the 1st NIRS Symposium on Reconstruction of Early Internal Dose in the TEPCO Fukushima Daiichi Nuclear Power Station Accident; Chiba, Japan; 10-11 Jul, 2012. p. 59-66.

11. Kim E, Yajima K, Hashimoto S, Tani K, Igarashi Y, limoto T, et al. Reassessment of internal thyroid doses to 1,080 children examined in a screening survey after the 2011 Fukushima Nuclear Disaster. Health Phys. 2020;118:36-52.

12. Tokonami S, Hosoda M, Akiba S, Sorimachi A, Kashiwakura I, Balonov M. Thyroid doses for evacuees from the Fukushima nuclear accident. Sci Rep. 2012;2:507.

13. Matsuda N, Kumagai A, Ohtsuru A, Morita N, Miura M, Yoshida $\mathrm{M}$, et al. Assessment of internal exposure doses in Fukushima by a whole body counter within one month after the nuclear power plant accident. Radiat Res. 2013;179:663-668.

14. Uchiyama K, Miyashita M, Sato H, Tanishima Y, Maeda S, Yoshikawa J, et al. A study of thyroid ${ }^{131}$ I activity of five human subjects exposed to a radioactive plume at Tamura City in Fukushima. Health Phys. 2015;109:573-581.

15. Kurihara O, Nakagawa T, Takada C, Tani K, Kim E, Momose T. Internal doses of three persons staying $110 \mathrm{~km}$ south of the Fukushima Daiichi Nuclear Power Station during the arrival of radioactive plumes based on direct measurements. Radiat Prot Dosimetry. 2016;170:420-424.

16. Takada C, Kurihara O, Kanai K, Nakagawa T, Tsujimura N, Momose $\mathrm{T}$. Results of whole body counting for JAEA staff members engaged in the emergency radiological monitoring for the $\mathrm{Fu}-$ kushima Nuclear Disaster. Proceedings of the 1st NIRS Sympo- sium on Reconstruction of Early Internal Dose in the TEPCO Fukushima Daiichi Nuclear Power Station Accident; Chiba, Japan; 10-11 Jul, 2012. p. 3-12.

17. Kurihara O, Li C, Lopez MA, Kim E, Tani K, Nakano T, et al. Experiences of population monitoring using whole-body counters in response to the Fukushima Nuclear Accident. Health Phys. 2018;115:259-274.

18. Kim E, Kurihara O, Tani K, Ohmachi Y, Fukutsu K, Sakai K, et al. Intake ratio of ${ }^{131} \mathrm{I}$ to ${ }^{137} \mathrm{Cs}$ derived from thyroid and whole-body doses to Fukushima residents. Radiat Prot Dosimetry. 2016;168: 408-418.

19. Kim E, Kurihara O, Kunishima N, Momose T, Ishikawa T, Akashi M. Internal thyroid doses to Fukushima residents-estimation and issues remaining. J Radiat Res. 2016;57(Suppl 1):i118-i126.

20. Hosoda M, Tokonami S, Akiba S, Kurihara O, Sorimachi A, Ishikawa $\mathrm{T}$, et al. Estimation of internal exposure of the thyroid to ${ }^{131} \mathrm{I}$ on the basis of ${ }^{134} \mathrm{Cs}$ accumulated in the body among evacuees of the Fukushima Daiichi Nuclear Power Station accident. Environ Int. 2013;61:73-76.

21. Kim E, Kurihara O, Kunishima N, Nakano T, Tani K, Hachiya M, et al. Early intake of radiocesium by residents living near the TEPCO Fukushima Dai-Ichi Nuclear Power Plant after the accident. Part 1: Internal doses based on whole-body measurements by NIRS. Health Phys. 2016;111:451-464.

22. Kunishima N, Kurihara O, Kim E, Ishikawa T, Nakano T, Fukutsu $\mathrm{K}$, et al. Early intake of radiocesium by residents living near the Tepco Fukushima Dai-ichi Nuclear Power Plant after the accident. Part 2: Relationship between internal dose and evacuation behavior in individuals. Health Phys. 2017;112:512-525.

23. Igarashi Y, Kim E, Hashimoto S, Tani K, Yajima K, limoto T, et al. Difference in the Cs body contents of affected area residents depending on the evacuation timepoint following the 2011 Fukushima nuclear disaster. Health Phys. Forthcoming 2020.

24. Kim E, Tani K, Kunishima N, Kurihara O, Sakai K, Akashi M. Estimation of early internal doses to Fukushima residents after the nuclear disaster based on the atmospheric dispersion simulation. Radiat Prot Dosimetry. 2016;171:398-404.

25. United Nations Scientific Committee on the Effects of Atomic Radiation. Sources, effects and risks of ionizing radiation: UNSCEAR 2013 Report. Volume I: Report to the general assembly. Scientific Annex A: Levels and effects of radiation exposure due to the nuclear accident after the 2011 great east-Japan earthquake and tsunami. New York, NY: United Nations Scientific Committee on the Effects of Atomic Radiation; 2014.

26. World Health Organization. Preliminary dose estimation from the nuclear accident after the 2011 Great East Japan Earthquake and Tsunami. Geneva, Switzerland: World Health Organization; 2012.

27. Murakami M, Oki T. Estimated dietary intake of radionuclides and health risks for the citizens of Fukushima City, Tokyo, and 
Osaka after the 2011 nuclear accident. PLoS One. 2014;9:e112791.

28. Kawai M, Yoshizawa N, Suzuki G. ${ }^{131}$ I dose estimation from intake of tap water in the early phase after Fukushima Daiichi Nuclear Power Plant Accident. Radiat Prot Dosimetry. 2018;179: 43-48.

29. Kamada N, Saito O, Endo S, Kimura A, Shizuma K. Radiation doses among residents living $37 \mathrm{~km}$ northwest of the Fukushima Dai-ichi Nuclear Power Plant. J Environ Radioact. 2012;110:84-89.

30. Ohba T, Hasegawa A, Suzuki G. Estimated thyroid inhalation doses based on body surface contamination levels of evacuees after the Fukushima Daiichi Nuclear Power Plant Accident. Health Phys. 2019;117:1-12.

31. Kurihara O, Kim E, Kunishima N, Tani K, Ishikawa T, Furuyama $\mathrm{K}$, et al. Development of a tool for calculating early internal doses in the Fukushima Daiichi nuclear power plant accident based on atmospheric dispersion simulation. EPJ Web Conf 2017;153:08008.

32. Kurihara O, Kim E, Suh S, Fukutsu K, Matsumoto M, Rintsu Y, et al. Reconstruction of early internal doses in the TEPCO FDNPS accident. Proceedings of the 2nd NIRS Symposium on Reconstruction of Early Internal Dose in the TEPCO Fukushima Daiichi Power Station Accident; Tokyo, Japan; 27 January, 2013. p. 140-162.

33. Hamada N, Ogino H. Food safety regulations: what we learned from the Fukushima nuclear accident. J Environ Radioact. 2012; 111:83-99.

34. Shinkarev SM, Kotenko KV, Granovskaya EO, Yatsenko VN, Imanaka T, Hoshi M. Estimation of the contribution of short-lived radioiodines to the thyroid dose for the public in case of inhalation intake following the Fukushima accident. Radiat Prot Dosimetry. 2015;164:51-56.

35. Nuclear Regulation Authority. Japanese guidelines for nuclear emergency response [Internet]. Tokyo, Japan; Nuclear Regulation Authority; 2019 [cited 2020 Apr 2]. Available from: https:// www.nsr.go.jp/data/000024441.pdf.

36. International Atomic Energy Agency. Criteria for use in preparedness and response for a nuclear or radiological emergency (IAEA Safety Standards). Vienna, Austria: International Atomic Energy Agency; 2011.

37. International Atomic Energy Agency. Operational intervention levels for reactor emergencies and methodology and their derivation. Vienna, Austria: International Atomic Energy Agency; 2017.

38. Li C, Ansari A, Etherington G, Jourdain JR, Kukhta B, Kurihara O, et al. Managing internal radiation contamination following an emergency: identification of gaps and priorities. Radiat Prot Dosimetry. 2016;171:78-84. 